\title{
Article
}

\section{Good things come in larger packages: size matters for fruit-feeding butterfly dispersal and diet breadth}

\author{
Geraldo B. Freire-Jr ${ }^{1 *}$, Thayane Silva ${ }^{2}$, Hernani Oliveira ${ }^{3}$, Chloe Collier ${ }^{1}$, Hanna Pamela ${ }^{2}$, Joao P. Dias ${ }^{2}$, Jessie P. \\ Santos ${ }^{4}$, Onildo J. Marini-Filho ${ }^{5}$, André V.L. Freitas ${ }^{4}$, Angela M. Smilanich ${ }^{1}$, Lee A. Dyer ${ }^{1}$, and Ivone R. Diniz ${ }^{2}$

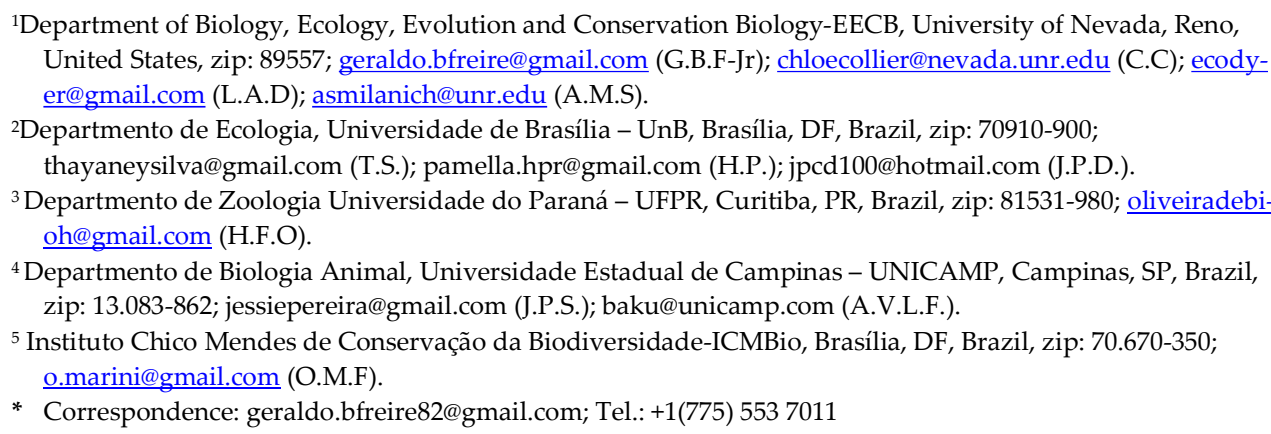

Abstract: Introduction: Body size is correlated with many aspects of an animal species' natural history, such as life span, abundance, dispersal capacity and diet breadth. However, contrasting trends have been reported for the relationship between body size and these ecological traits. Methods: Butterfly species from fruit-feeding guilds were used to investigate whether body size correlates with species abundances, dispersal, permanence, and diet breadth in a Neotropical savanna in Brazil (Cerrado). We used Blomberg's K and Phylogenetic Generalized Least Squares models (PGLS) to measure phylogenetic signal strength in species traits, and to estimate size-dispersal-diet breadth associations while taking shared ancestry into account. Results: 539 individuals from 27 species were captured, and 190 individuals were recaptured, representing a $35 \%$ recapture rate. We found that body size negatively influenced butterfly abundance. In contrast, body size was positively associated with dispersal levels, distance traveled, number of traps visited, individual permanence, and diet breadth. These results indicate that larger butterflies have a greater proportion of dispersing individuals over longer distances, as they permanence were detected over longer periods than their smaller relatives. Moreover, larger butterflies are more generalized, based on the number of host plant families and genera they consume. Smaller butterflies demand fewer resources, which is reflected in their higher survival in small patches, and may explain their lower dispersal ability, and higher diet specialization. Nevertheless, lower dispersal ability, if not compensated by large population sizes, may threaten small-bodied species inhabiting environments with intense deforestation rates, such as the Cerrado. Conclusions: Body size positively influences dispersal and diet breadth in the fruit-feeding butterflies collected in this study.

Keywords: Body-size; Cerrado; Evolutionary history; Nymphalidae; Phylogeny; Species traits

\section{Introduction}

Dispersal is a key process for species survival and persistence in the environment. It can help to reduce intraspecific competition and promote species coexistence [1]. This is especially true for environmental changes that require a spatial response of populations, such as shifting climatic niche or maintaining connections among populations in increasingly fragmented landscapes [1]. Accordingly, increasing efforts have been made to 
understand the conditions that modulate dispersal [2]. Identifying which life history traits co-vary with dispersal related traits should enable us to make predictions about species responses in the face of environmental changes [3,4]. This is particularly relevant for species inhabiting environments with high deforestation rates, such as a Neotropical Savannah known as the Cerrado in Brazil [2,5].

Body size is a morphological trait related to dispersal, as well as many other aspects of a species' natural history, such as life span, abundance, and diet breadth [6-9]. Since body size is strongly associated with metabolism and resource use [6], its relationship with species abundance can also reveal how resources are partitioned in biotic communities [10-11]. In many cases, larger butterflies have higher dispersal ability, which can be an advantage for reaching and colonizing new habitat patches, compared to their smaller relatives [13,14]. However, in fruit-feeding butterflies (Nymphalidae), evidence suggests that larger butterflies are less abundant and have lower dispersal ability, thus making them more vulnerable to habitat loss compared to their smaller relatives $[12,13]$. Although the interplay between body size, abundance, and dispersal is still not fully understood for papilionoids (butterflies), it suggests a trade-off between abundance and dispersal ability $[2,14]$.

The relationship between body size and diet breadth has been studied over many decades, especially for insect herbivores $[15,16]$. From these studies, the common expectation is that "a jack of all trades is a master of none," which, in an ecological context, refers to the idea that generalists might be able to consume a wide range of resources but will not be particularly well adapted to any of them [17]. In this context, most studies show that specialized species tend to be smaller [18, 19], more abundant, and more spatially restricted than their larger relatives [20,19]. However this pattern is not universal, and some studies report that such relationships do not exist for some insect clades [21, 22]. Understanding how diet breadth mediates these species trait relationships, such as body size, abundance, and dispersal ability, can contribute in identifying factors influencing community composition, which may also inform conservation programs, especially in tropical regions $[19,20]$.

As deforestation increases, the connectivity between forest patches decreases, which in turn can affect the ability of animal species to disperse and to colonize new habitats $[4,7]$. However, trait-environmental relationships may not be exclusively explained by present-day ecological processes, they can also reflect the evolutionary history shared by different species in ecological communities [23,24]. Thus, phylogenetic information, especially when combined with both ecological and functional data, is essential for a more accurate understanding about community assembly [4,25]. The evaluation of phylogenetic signal strength for butterfly traits has been recently utilized to better understand determinants of butterfly assemblages along spatial gradients in the Amazon forest $[26,4]$. Nevertheless, this approach remains underutilized in studies attempting to uncover the influence of body size on abundance, dispersal ability, and diet breadth for most insect populations, particularly in the Cerrado [7].

Using fruit-feeding butterflies (Nymphalidae), we estimated population size, dispersal ability, and diet breadth of different species in the Cerrado, and addressed the two questions below for the assemblages we sampled:

1) How is body size associated with abundance, dispersal level, dispersal distance, permanence, and diet breadth of different fruit-feeding butterfly species? Due to strong associations between body size and metabolism, and the tradeoff between abundance and dispersal ability demonstrated for other taxa [2], we predicted that larger butterflies would be less abundant but would have greater dispersal capacity when compared with their smaller relatives [7,8]. Moreover, based on the "a jack of all trades is a master of none" paradigm, we also predicted that larger species have wider diet breadth and disperse longer distances compared to their smaller relatives.

2) Does phylogeny partly account for the relationship between body size, diet breadth, abundance, and dispersal of these butterflies? Body size is a highly conserved 
trait in the fruit-feeding butterfly guild [23,4]. Thus, we predicted at least an indirect effect of phylogeny on dispersal ability and diet breadth, but not on species abundance since this trait is generally defined by a complex interaction of many environmental factors [27-29].

\section{Materials and Methods}

2.1 Study site and sampling design

An intensive butterfly survey was conducted during 35 consecutive days in 2013 (Feb-11 to Mar-17) in Fazenda Água Limpa (4,500 ha). This period corresponds to the end of the rainy season, a period of higher fruits ripening in the Cerrado [29]. The study site is inside a 10,000ha protected area [29] near Brasilia, DF, Brazil (Fig. 1). This period was chosen to optimize the sampling effort and has been used as a baseline for previous reports for these butterflies in the Cerrado [29].

A grid of 1.8 ha $(150 \times 120 \mathrm{~m})$ with four linear transects (P1-P4) was set up in the savannah-gallery forest ecotone. The transects in this grid were $40 \mathrm{~m}$ apart from each other. Six Van Someren-Rydon "bait-traps" (30 m apart) were equally distributed from savannah through gallery forest in each linear transect (Fig 1) for a total of 24 bait-traps. A mixture prepared with bananas and sugarcane $(\sim 50 \mathrm{ml})$ was fermented for $48 \mathrm{~h}$ and added to each bait-trap, following an established sampling protocol for these butterflies [12]. Using a permanent ink pen, we marked all captured butterflies, which received an individual number at the ventral side of the forewing. After the butterflies were marked, they were released, and the subsequent recaptures were recorded.

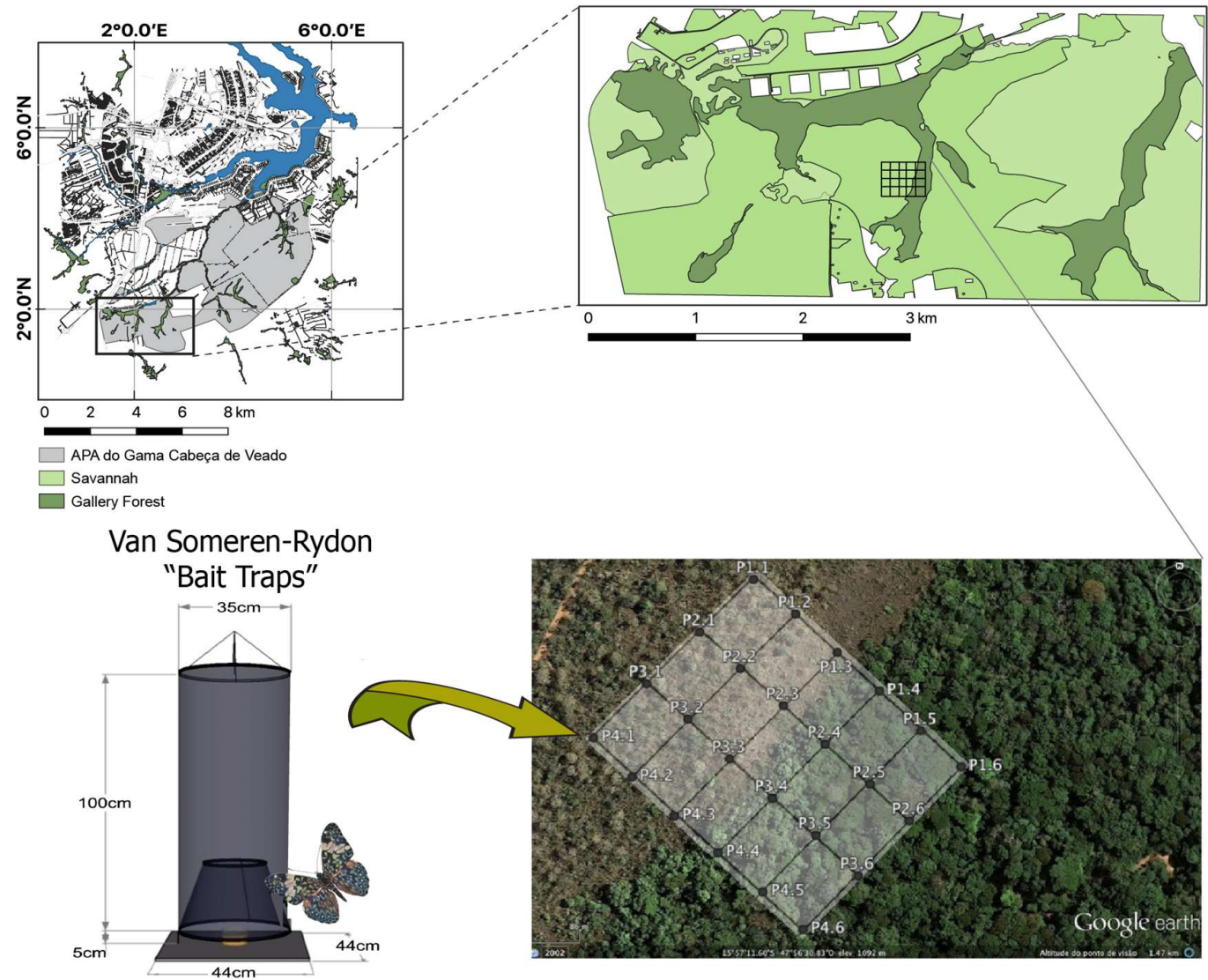

Figure 1. Experimental 1.8 ha (150 vs $120 \mathrm{~m}$ ) grid created at "Fazenda Água Limpa", located at "APA do Gama Cabeça de Veado" a 10,000 ha conservation unity near Brasília, Distrito Federal, Central Brazil.

\subsection{Fruit feeding butterflies}


Fruit-feeding butterflies (Nymphalidae) use rotting fruit as their major food source. Nymphalids comprise about $50-75 \%$ of all Neotropical butterfly species richness $(\sim 6,000$ spp), are easily sampled with a standardized trap protocol, and respond to environmental changes in space and time. Moreover, their life-history traits and morphology are well studied. For these reasons, fruit-feeding butterflies are well suited for quantitative studies of dispersal and are excellent model organisms for studies in ecology and evolution $[2,12,25,30,31,32]$.

2.3 Phylogenetic, Morphological and ecological traits

The phylogenetic relationships of fruit-feeding butterflies were estimated using the $\mathrm{R}$ package phytools [33]. Species divergence time was estimated based on the most recently published Nymphalid phylogeny [34]. Species from the published phylogeny that were absent from our community were pruned. To include species of our community that were absent in the published phylogeny, we consulted the topologies from the specific taxonomic literature and specialists. The length of the new branches created by the insertion of these species was determined as the half of branch lengths from the same node on the original tree.

We photographed 10 specimens of each species to quantify forewing length (FWL) using ImageJ software [35]. We considered FWL a surrogate for body size, as the correlation between wingspan and body length is about 0.8 in fruit-feeding butterflies [13].

The following variables were collected for each species: a) relative abundance (n): number of individuals captured in each species; b) dispersal level (\%): proportion of dispersing individuals for each species; c) dispersal distance $(\mathrm{m})$ : cumulative distance dispersed by each individual through the sampling period; d) visited traps (v.t): number of traps registered by each individual; e) permanence (days): period of time between the first and the last capture recorded for each individual in the study site; f) diet breadth: the number of host plant families, genera, and species each butterfly species is known to consume (36). The dispersal distances were calculated based on the lowest distance between two or more traps visited by each individual.

\subsection{Statistical analysis}

We calculated Blomberg's $\mathrm{K}$ to estimate a phylogenetic signal for all species traits (body size, abundance, dispersal distance and rates, number of visited traps, permanence, and diet breadth) $[37,38]$. Then we utilized phylogenetic generalized least square models (PGLS) to estimate linear relationships between body size and the dispersal and diet breadth traits [39]. All analyses were performed using the R software packages ape, picante, phytools [40].

\section{Results}

A total of 539 butterflies, in 13 genera and 27 species were captured, with 190 individuals recaptured at least once (35\% of recapture rate). The three most abundant species were Pareuptychia ocirrhoe (Fabricius, 1776) $(\mathrm{N}=174)$, Hamadryas feronia (Linnaeus, 1758) $(\mathrm{N}=70)$, and Cissia phronius (Godart, [1824]) $(\mathrm{N}=47)$, while nine species were represented by less than five individuals each (Appendix A). The tribe Satyrini $(\mathrm{N}=374 ; 59 \%)$, and Biblidinae $(\mathrm{N}=179 ; 28 \%)$ were the most abundant clades, whereas Charaxinae $(\mathrm{N}=13$, $2 \%)$, and Nymphalinae $(\mathrm{N}=14 ; 2 \%)$ were those with the lowest abundance.

Qualitatively, there was phylogenetic signal for size: Satyrini presented smaller body sizes, while Brassolini and Morphini presented the largest body sizes (Appendix A). Considering all the measured traits, only body size and diet breadth were statistically associated with the evolutionary history shared by these species of butterflies (Table 1), indicating trait conservatism, whereby close lineages have similar body sizes and diet breadth. There was a negative relationship between body size and abundance $(\beta=-0.09$; $\mathrm{p}=0.01$, Fig. 2a), while accounting for phylogenetic relatedness.

The PGLS analyses support the hypothesis that body size is positively associated with dispersal levels (Fig. 2b), dispersal distance (Fig. 2c), number of visited traps (Fig. $2 d$ ), individual permanence (Fig. 2e), and diet breadth (Figures $2 f$ and $2 g$, for number of 
host plant families and genera respectively). These results altogether indicate that compared to smaller species, larger butterflies are less abundant and with a greater proportion of individuals that disperse over longer distances. The larger species presented higher permanence when compared with their smaller relatives (Table 2). Moreover, larger species had broader diet breadths than smaller species, based on the number of families and genera of known larval host plants (Table 2).

Dispersal levels were lowest for Paryphthimoides poltys (13\% had dispersed), Cissia phronius and Pareuptychia ocirrhoe (16\%), whereas Zaretis isidora (66\%), Eryphanis automedon $(60 \%)$, and Memphis moruus (50\%) had the greatest proportion of collected individuals that had dispersed (Appendix A). For higher taxa, Charaxinae (55\%) and Brassolini (37\%) had the greatest dispersal levels, while Satyrini (15\%) had the lowest. Among the recaptured individuals, $88(60 \%)$ dispersed relatively short distances $(0-70 \mathrm{~m}), 41(27 \%)$ dispersed intermediate distances (71-141 m), and $18(13 \%)$ dispersed the longest distances $(142-422 \mathrm{~m})$. The shortest traveled distances were recorded for Callicore sorana, Opsiphanes invirae, and Pareuptychia ocirrhoe, while the longest distances were recorded for Eryphanis automedon, Catonephele acontius and Cissia phronius (Appendix A).

Individuals of C. acontius, Hamadryas feronia, and Hamadryas februa were collected for longer periods in the study site $(6.3,5.5,5.5$ days between the first and last capture, respectively), while Yphthimoides renata, Zaretis isidora, and Taygetis laches were those with the shortest periods between the first and the last capture (2.1, 2.3, 2.5 days, respectively) (Appendix A).

Three species, Morpho helenor, Caligo illioneus, and Eryphanes automedon are the most generalists based on the number of known larval host plant families $(13,8$ and 6 , respectively) and genera (32, 12 and 12, respectively). Morphini and Brassolini are the most generalized nymphalid clades among those included in our study (Appendix A). Overall, the Satryrini is the most specialized nymphalid clade examined here, with five out eight Satyrini species using only one or two host plant families, genera, and species (Appendix A).

\section{Discussion}

Trait-dispersal relationships

A clear phylogenetic signal was found for both body size and diet breadth, indicating trait conservatism where close lineages of fruit-feeding butterflies have similar body sizes $[15,4]$, and similar host plant associations. It reiterates the importance of considering the evolutionary history of clades when examining their complex trait-environment relationships.

Among the larger species, charaxines have a large mass of flight muscles, and they are excellent flyers, inhabiting open areas such as savannahs and forest canopies $[4,7,21]$. These traits are likely to contribute to their high dispersal level (50\%), as reported here. Moreover, larger butterflies are expected to demand more resources, which may force them to disperse in search for more suitable habitats [2]. On the other hand, smaller species may be better able to survive in small patches, reflecting their lower dispersal [2]. If true, the patchy distribution of small-bodied species, if not compensated by their larger population sizes, should constrain their persistence in environments with intense deforestation, such as the Cerrado. Thus, special efforts should be considered for conservation of these small and more specialized butterflies.

The degree of dietary specialization may be an important part of the mechanisms that generate these patterns of dispersal. In this study, we demonstrated the larger and less abundant species have higher dispersal patterns and broader diet breadths compared to their smaller relatives. These associations corroborate the evidence found in a long-term study from Ecuador, in which generalist species are widespread and locally less abundant $[18,19,20]$. Further studies are required to confirm the causal mechanisms operating to generate the observed patterns, and to test the correlations between fine-scale movements and large-scale dispersal. 
Table 1. Phylogenetic signal values (Blomberg's K and P-value) of the species-traits measured in fruit feeding butterflies captured in Fazenda Água Limpa, Brasília, Brazil.

\begin{tabular}{lcccc}
\hline \multicolumn{1}{c}{ Traits } & Blomberg's K & P-value & \\
\hline Body size & 1.1 & 0.001 & $* * *$ \\
Diet breadth (Family of plants) & 1.08 & 0.001 & $* * *$ \\
Diet breadth (Genera of plants) & 0.84 & 0.002 & $* *$ \\
Diet breadth (Species of plants) & 0.79 & 0.01 & $* *$ \\
Dispersal level & 0.76 & 0.07 & ns \\
Dispersal distance & 0.53 & 0.53 & ns \\
Visited traps & 0.39 & 0.66 & ns \\
Permanence (days) & & & \\
Abundance & 0.39 & 0.78 & $\mathrm{~ns}$ \\
\hline
\end{tabular}

$(* *)$ Indicates $\mathrm{p} \leq 0.001 ;\left(^{*}\right)$ Indicates $\mathrm{p} \leq$ 0.05 ; (ns) indi-

cates non-significant.

Table 2. Phylogenetic generalized least squares (PGLS) between body size and other species traits in fruit-feeding butterflies captured in Fazenda Água Limpa, Brasília, Brazil.

\begin{tabular}{lcccc}
\hline \multicolumn{1}{c}{ Traits } & F & Beta & P-value & \\
\hline Abundance & 7.2 & -0.09 & 0.01 & $* *$ \\
Dispersal level & 9.69 & 1.17 & 0.01 & $* *$ \\
Dispersal distance & 9.09 & 0.22 & 0.01 & $* *$ \\
Visited traps & 9.69 & 0.13 & 0.01 & $* *$ \\
Permanence (days) & 4.64 & 0.13 & 0.04 & $*$ \\
Diet Breadth (Family of plants) & 16.23 & 3.8 & 0.001 & $* * *$ \\
Diet Breadth (Genera of plants) & 4.64 & 0.79 & 0.04 & $*$ \\
Diet Breadth (Species of plants) & 1.83 & -0.03 & 0.81 & ns \\
Habitat (gallery forest) & & & & \\
\hline
\end{tabular}

$\left.{ }^{* * *}\right)$ Indicates $\mathrm{p} \leq 0.001 ;\left(^{* *}\right) \mathrm{p} \leq 0.01 ;\left({ }^{*}\right) \mathrm{p} \leq 0.05 ;(\mathrm{ns})$ indicates non-significant. 
(a)

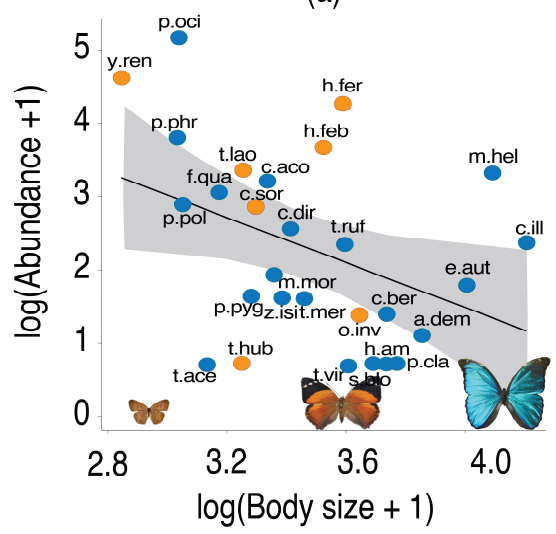

(d)

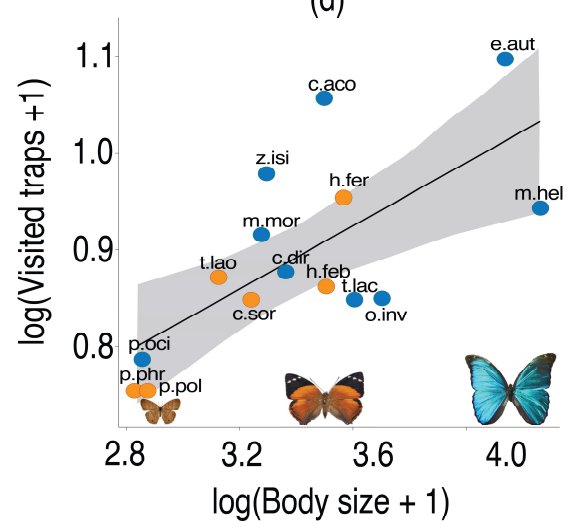

(b)

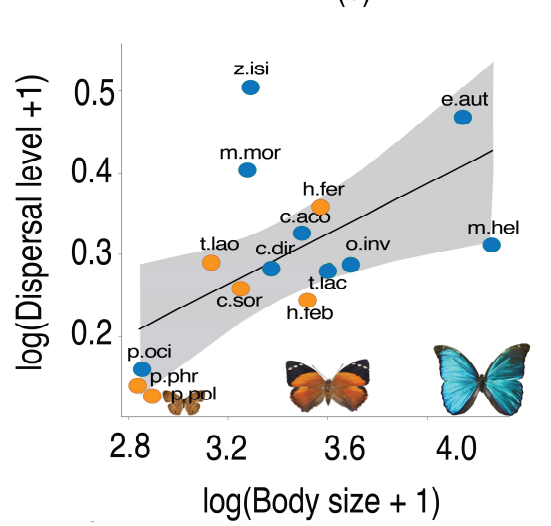

(e)

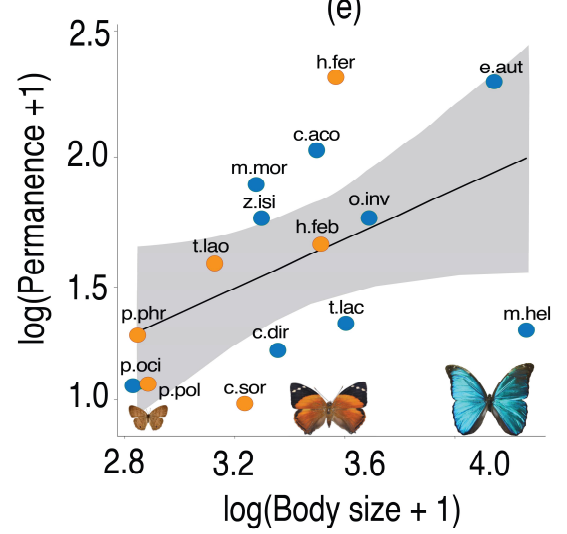

(g)

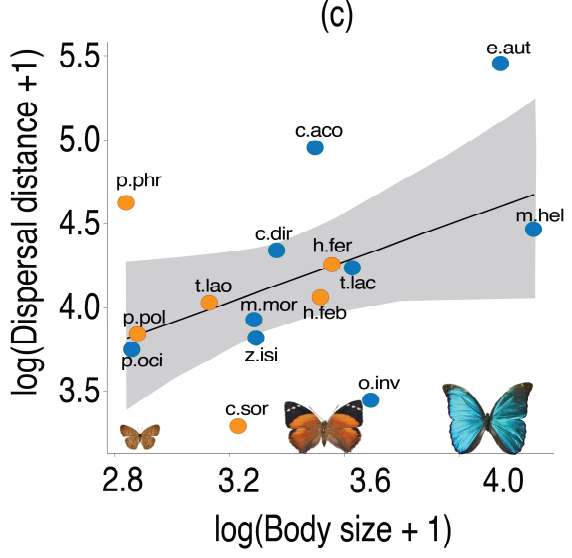

(f)

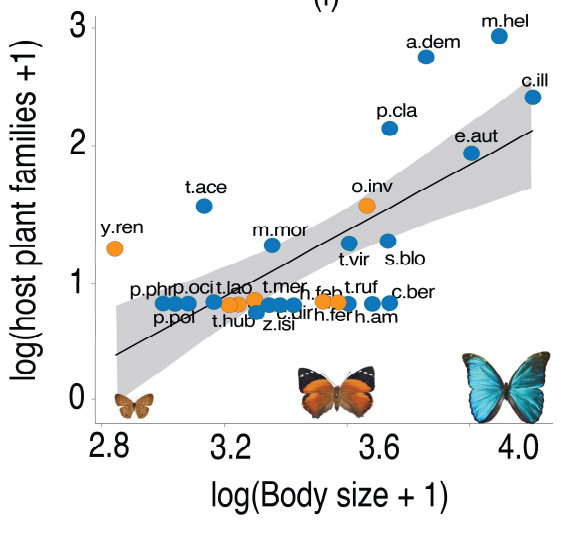

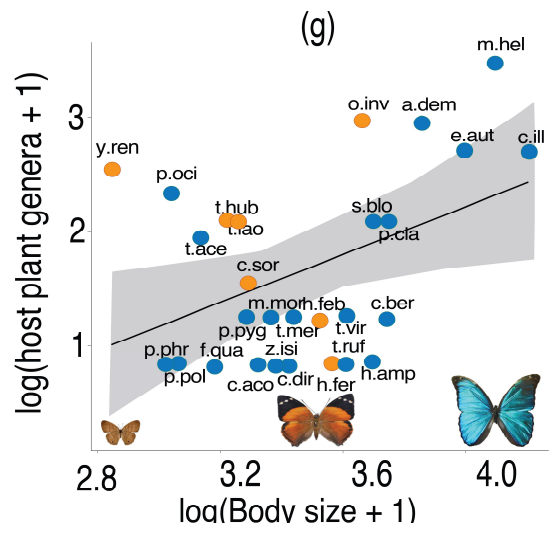

Figure 2. Phylogenetic generalized least squares (PGLS) results for the associations between body size and: a) dispersal level; b) dispersal distance; and c) visited traps; d) individual permanence; e) host plant families; and g) host plant genus of fruit-feeding butterflies captured in 35 days in the Cerrado of Fazenda Água Limpa, Brasília, Brazil. Blue circles represent the forest specialist species, while savannah specialist species are represented by the orange circles. The overall raw effect size of body size on associated variables can be interpreted as a $1 \mathrm{~cm}$ increase in wing size yielding 0.19 decrease in abundance, 1.17 increase in levels of dispersal, 0.22 change in distance, 0.13 in traps visited, 0.13 in permanence, 3.8 and 0.79 in diet breadth based on host plant families and genera, respectively. 


\section{Conclusions}

Body size was a phylogenetically constrained trait in our study, corroborating the idea that phylogeny should be considered in studies on size-dispersal relationships. Clades comprised of large-bodied butterflies had a greater proportion of dispersing individuals, which dispersed over longer distances, were detected through longer periods, and feed on a higher number of host plant families and genera than their smaller relatives. In addition, the ability to disperse was higher in generalist compared to specialist butterflies, which suggests that specialists form isolated populations that are more susceptible to drift.

Supplementary Materials: The following are available online at www.mdpi.com/xxx/s1, Figure S1: title, Table S1: title.

Author Contributions: G.B.Freire-Jr, I.R.Diniz, and O.Marini-Filho conceived, designed the experiment, and have edited the manuscript; T.Silva, J.P.Dias, and. H.Pamela performed the experiments; G.B.Freire-Jr analyzed the data; J.P. Santos, and A.V.L.Freitas contributed with phylogenetic analysis; G.B.Freire-Jr, C. Chloe, H.Oliveira, A. Smilanich, and Lee Dyer wrote the paper.

Funding: This research was funded by Coordination of Improvement of Higher Education (CAPES) and the National Council for Scientific and Technological Development (CNPq) through the PVE Program and PRONEX CNPq/FAPDF (research fellowship grant: CNPq-303076/2013).

Institutional Review Board Statement: "Not applicable."

Data Availability Statement: The data presented in this study are available in [insert article or supplementary material here]

Acknowledgments: The authors thank Nayara F. Araújo for their assistance with fieldwork. Mardônio and Vandélio drove us safely during all field expeditions. Thanks to the University of Brasilia for the logistical support. G.B.F.Jr and I.R.D are grateful for the financial support provided by the Coordination of Improvement of Higher Education (CAPES) and the National Council for Scientific and Technological Development $(\mathrm{CNPq})$ through the PVE Program and PRONEX CNPq/FAPDF (research fellowship grant: CNPq-303076/2013), respectively.

Conflicts of Interest: The authors declare no conflict of interest 
Appendix A. Forewing length (FLW); abundance (N); dispersal level (\%); dispersal distance (m); permanence (days); and diet breadth based on the number of family, genera and species of host plants (Fam/ Gen/ Spp, respectively) of fruit-feeding butterfly species captured in 35 consecutive days at Fazenda Água Limpa, Brasília, Brazil.

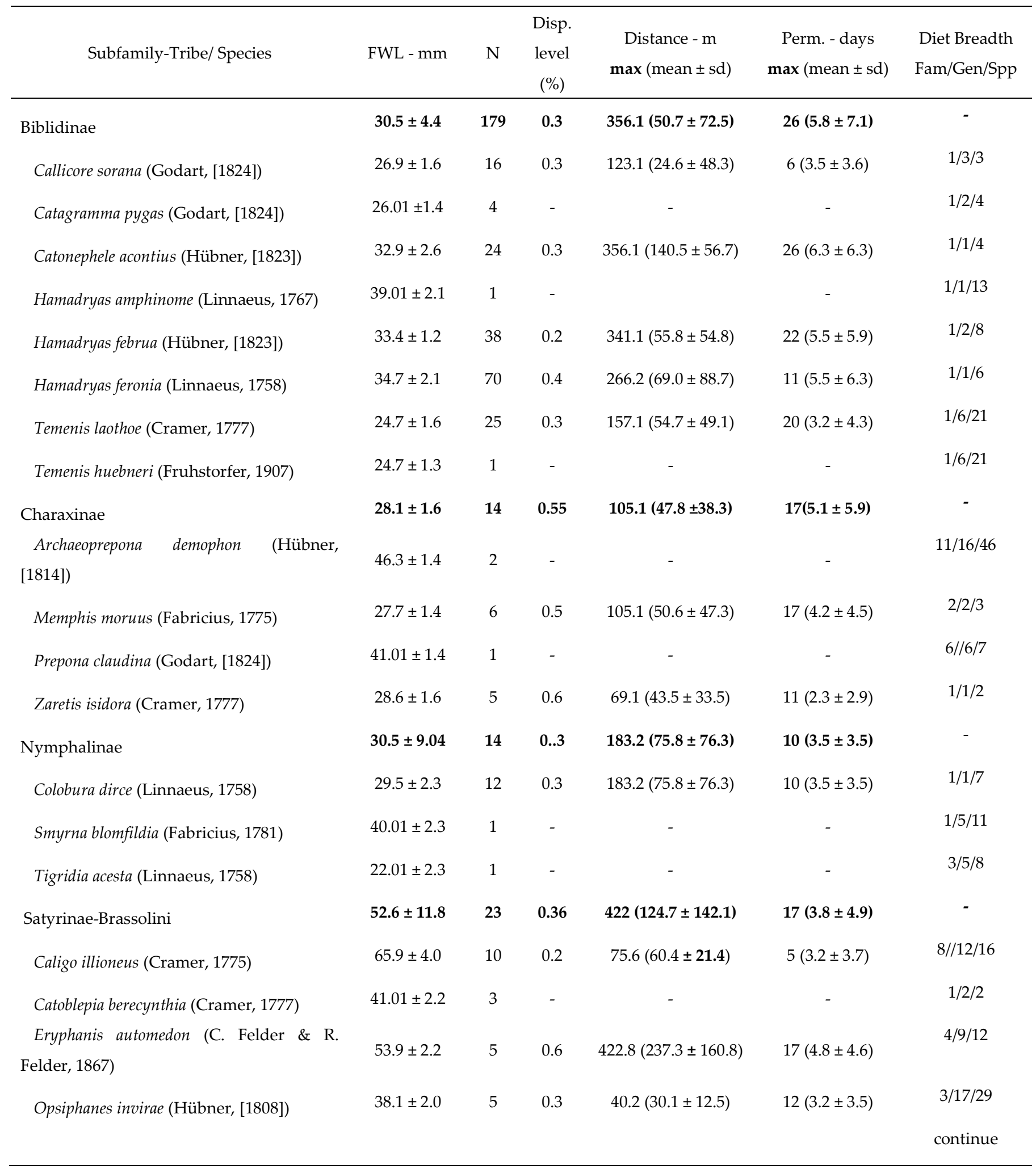


10 of 12

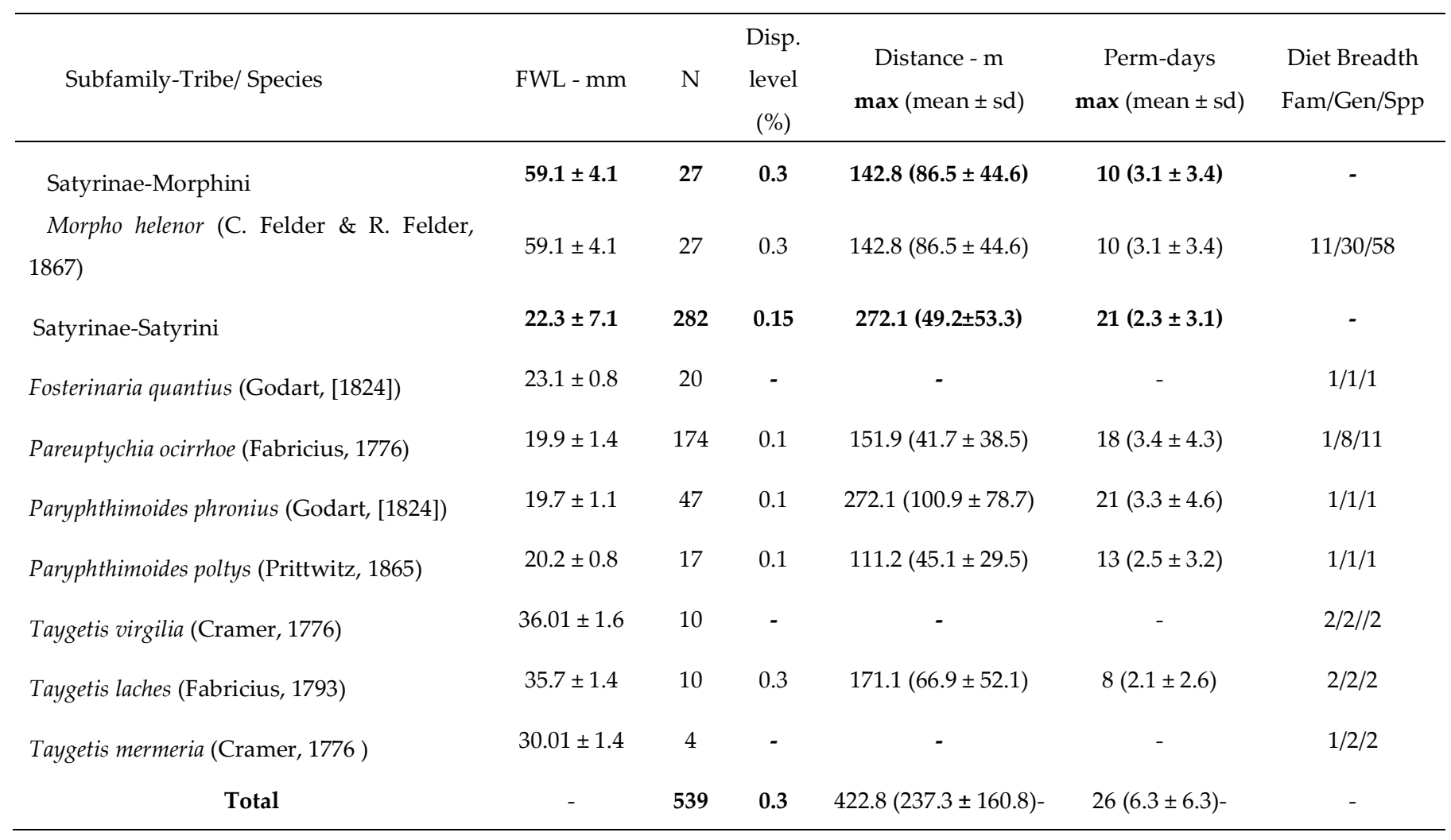




\section{References}

1. Phillips, B.L.; Brown, G.P; Shine, R. Evolutionarily accelerated invasions: the rate of dispersal evolves upwards during the range advance of cane toads. J. Evol. Biol 2010, 23, 2595-2601.

2. Stevens, V.M.; Trochet, A.; Dyck, H.V.; Colbert, J.; Baguete, M. How is dispersal integrated in life histories: a quantitative analysis using butterflies. Ecol. Letters 2012, 15, 74-86.

3. Fountain-Jones, N.M.; Baker, S.C.; Jordan, G.J. Moving beyond the guild concept: developing a practical functional trait framework for terrestrial beetles. Ecol. Entom 2015, 40,1-13.

4. Spaniol, R.L.; Duarte, L.S.; Mendonça-Jr, M.S; Iserhard, C.A. Combining functional traits and phylogeny to disentangling Amazonian butterfly assemblages on anthropogenic gradients. Ecosphere 2019, DOI: 10(8):e02837. 10.1002/ecs2.2837.

5. Faleiro, F.; Machado, R.B.; Loyola, R.D. Defining spatial conservation priorities in the face of land-use and climate change. Biol Conserv 2013, 158, 248-257.

6. Brown, J.H.; Gillooly, J.F.; Allen, A.P.; Savage, V.M.; West, G.B. Toward a metabolic theory of ecology. Ecol 2004, 85, 1771-1789.

7. Marini-Filho, O.J.; Martins, R. P. Nymphalid butterfly dispersal among forest fragments at Serra da Canastra National Park, Brazil. J. Ins. Conserv 2010, 14, 401-411.

8. Gillespie, M.A.K.; Birkemoe, T.; Sverdrup-Thygeson, A. Interactions between body size, abundance, seasonality and phenology in forest beetles. Ecol Evol 2017, 7, 1091-1100.

9. Molleman, F.; Zwaan, B.J.; Brakefield, P.M.; Carey, J.R.; Extraordinary long life spans in fruit-feeding butterflies can provide window on evolution of life span and aging. Exper Geron 2007, 42, 472-482.

10. White, E.P.; Ernest, S.K.M.; Kerkhoff, A.J.; Enquist, B.J. Relationships between body size and abundance in ecology. Trends Ecol Evol 2007, 22, 323-330.

11. Ribeiro, D. B.; Freitas, A.V.L. Large-sized insects show stronger seasonality than small-sized ones: a case study of fruit-feeding butterflies. Biol J Linn Soc 2011, 104, 820-827.

12. Uehara-Prado, M.; Brown, K.S.Jr.; Freitas, A.V.L. Species richness, composition and abundance of fruit- feeding butterflies in the Brazilian Atlantic Forest: comparison between a fragmented and a continuous landscape. Glob Ecol \& Biogeo 2007, 16, 4354.

13. Shahabuddin, G.; Ponte, C.A. Frugivorous butterfly species in tropical forest fragments: correlates of vulnerability to extinction. Biodiv Conserv 2005, 14, 1137-1152.

14. Skórka, P.; Kudlek, J.; Pepkowska, A.; Sliwinska, E.B.; Settele, J; Woyciechowski, M. Movements and flight morphology in the endangered large blue butterflies. C Eur J of Biol 2013, 7, 662-669.

15. Ehrlich, P.R.; Raven, P.H. Butterflies and plants: A study in coevolution. Evolution 1964, 18, 586-608.

16. Forister, M.L.; Dyer, L.A.; Singer, M.S.; Stireman, J.O.; Lill, J.T.; Revisiting the evolution of istepecological specialization, with

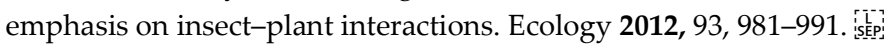

17. MacArthur, R.H.; Geographical ecology: patterns in the distribution of species. New York, Harper \& Row, 1972. is isp:

18. Davis, R.B.; Õunap, E.; Javois, J.; Gerhold, P.; Tammaru, T. Degree of specialization is related to body size in herbivorous insects: A phylogenetic confirmation. Evol 2012, doi:10.1111/j.1558-5646.2012.01776.x

19. Hjalmarsson, A.; Bergsten, J.; Monaghan, M.T. Dispersal is linked to habitat use in 59 species of water beetles (Coleoptera: Adephaga) on Madagascar. Ecography 2015, 38, 732-739.

20. Sudta, C.; Salcido, D.M.; Forister, M.L.; Walla, T.; Villarín-Cortez, S.; Dyer, L.A. Jack-of-all trades paradigm meets long-term data: generalist herbivores are more widespread and locally less abundant. bioRixiv 2020, doi: 10.1101/2020.11.27.401778.

21. Gaston, K. J. Patterns in local and regional dynamics of moth populations. Oikos 1988, 53, 49-57.

22. Reavey, D. Egg size, first instar behavior and the ecology of Lepidoptera. J. Zool 1992, 227, $277-297$.

23. Pavoine, S.; Baguette, M.; Stevens, V.M.; Leibold, M.A.; Turlure, C.; Bonsall, M.B. Life history traits, but not phylogeny, drive compositional patterns in a butterfly metacommunity. Ecol 2014, 95, 3304-3313.

24. Duarte, L.D.S.; Debastiani, V.J.; Carlucci, M.B.; Diniz-Filho, J.A.F. Analyzing community-weighted trait means across environmental gradients: Should phylogeny stay or should it go? Ecol 2014, 99, 385-398.

25. Iserhard, C.A.; Duarte, L.; Seraphim, N.; Freitas, A.V.L. How urbanization affects multiple dimensions of biodiversity in tropical butterfly assemblages. Biodiv \& Conserv 2019. 10.1007/s10531-018-1678-8

26. Graça, M.B.; Pequeno, P.A.C.L.; Frankling, E.; Morais, J.W. Coevolution between flight morphology, vertical stratification and sexual dimorphism: What can we learn from tropical butterflies? J Evol Biol 2017, 30, 1862-1871.

27. Santos, A.C.; Sales, P.C.L.; Ribeiro, D.B. Habitat conversion affects beta diversity in frugivorous butterfly assemblages. S Neot Fau Envir 2020, 55, 180-192. 
28. Lourenço, G.M.; Soares, G.R.; Santos, T.P.; Dáttilo, W.; Freitas, A.V.L.; Ribeiro, S.P. Equal but different: Natural ecotones are dissimilar to anthropic edges. PlosOne 2019. available at: https://doi.org/10.1371/journal.pone.0213008.

29. Freire Jr. G.B.F.; Diniz, I.R. Temporal dynamics of fruit-feeding butterflies (Lepidoptera: Nymphalidae) in two habitats in a Brazilian environment. Flo Entomol 2015, 98, 1207-1216.

30. DeVries, P.J. Stratification of fruit-feeding nymphalid butterflies in a Costa Rican rainforest. J. Res. Lepid 1988, $26,98-108$.

31. Freitas, A.V.L.; Iserhard, C.A.; Santos, J.P.; Carreira, J.Y.O.; Ribeiro, D.B.; Melo, D.H.A.; Rosa, A.H.B.; Marini-Filho, O.J.; Accacio, G.M.; Uehara-Prado, M.; Studies with butterfly bait traps: an overview. Rev Col Entomol 2014, 40, $209-218$.

32. Espírito-Santo, M.M.; Leite, M.E.; Silva, J.O.; Barbosa, R.S.; Rocha, A.M.; Anaya, F.C.; Dupin, M.G.V. Understanding patterns of land-cover change in the Brazilian Cerrado from 2000 to 2015. Philos $\mathrm{T}$ R Soc B 2016, available at: https://doi.org/10.1098/rstb.2015.0435

33. Revell, L. J. phytools: An R package for phylogenetic comparative biology (and other things). Methods Ecol Evol 2012, DOI: 3 217-223. doi:10.1111/j.2041-210X.2011.00169.x.

34. Wahlberg, N.; Leneveu, J.; Kodandaramaiah, U.; Pena, C.; Nylin, S.; Freitas, A.V.L.; Brower, A.V.Z. Nymphalid butterflies diversify following near demise at the Cretaceous/Tertiary boundary. Proc Biol Sci 2009, 276, 4295-4302.

35. Schneider, C.A.; Rasband, W.S.; Eliceiri, K.W. NIH image to ImageJ: 25 years of image analysis. Focus on Bioim Inf 2012, 9, 671675.

36. Beccaloni, G.W.; Hall, S.K.; Viloria, A.L.; Robinson G.S. Catalogue of the hostplants of the Neotropical Butterflies/Catálogo de las plantas huésped de las mariposas Neotropicales. In: Monografias Tercer Milenio. Zaragoza, S.E.A., RIBES-CYTED, The Natural History Museum, Instituto Venezolano de Investigaciones Científicas, 2008, vol. 8, 536p.

37. Blomberg, S.P.; Garland, T.; Ives, A.R. Testing for phylogenetic signal in comparative data: Behavioral traits are more labile. Intern J Org Evol 2013, 57, 717-745.

38. Paradis, E.; Schliep, K. ape 5.0: an environment for modern phylogenetics and evolutionary analyses in R. Bioinf 2019, 35, 526528. DOI: https://doi.org/10.1093/bioinformatics/bty633.

39. Kembel, S.; Cowan, P.D.; Helmus, M.R.; Cornwell, W.K.; Morlon, H.; Ackerly, D.D.; ... Webb, C.O. Picante: R tools for integrating phylogenies and ecology. Bioinf 2010, 26, 1463-1464. 